\title{
Fiber Types of the Intrinsic Whisker Muscle and Whisking Behavior
}

\author{
Tae-Eun Jin, Veit Witzemann, and Michael Brecht \\ Department of Cell Physiology, Max-Planck-Institute for Medical Research, D-69120 Heidelberg, Germany
}

\begin{abstract}
Some rodent species show rhythmic bouts of vibrissal protractions and retractions, referred to as whisking, that are among the fastest movements performed by mammals. To better understand the muscular basis of whisking, we compared (1) whisker movements of two whisking species (mouse, rat) and a non-whisking species (guinea pig), (2) the muscle fiber composition of intrinsic whisker muscles of whisking and a non-whisking species, and (3) the muscle fiber composition of intrinsic whisker muscles and of selected skeletal muscles. Using high-speed videography, we found that mice, rats, and guinea pigs can generate fast and large-amplitude whisker movements. Guinea pigs do not show bouts of fast, strictly rhythmic whisker movements, and the average speed of their whisker movements is much lower than in mice and rats. Analysis of mRNA expression of myosin heavy chain isoforms, myofibrillar ATPase staining, and antibody labeling indicate that in all three species intrinsic whisker muscles are composed predominantly of type $2 \mathrm{~B}$ muscle fibers. Intrinsic whisker muscles of mice consisted of type $2 \mathrm{~B}(\geq 90 \%)$ and type $2 \mathrm{D}$ fibers. In rats we observed, in addition to type $2 \mathrm{~B} / 2 \mathrm{D}$ fibers, $\sim 10 \%$ of slow type 1 fibers, and in guinea pigs we observed $\sim 3 \%$ of slow type 1 fibers and $20 \%$ of type $2 \mathrm{~A}$ fibers. Type $2 \mathrm{~B}$ fibers have high levels of anaerobic glycolytic enzymes providing a rapid source of ATP and high maximum velocity of contraction but are less fatigue resistant than other muscle fiber types. The high percentage of type $2 \mathrm{~B}$ fibers distinguishes the intrinsic whisker musculature from skeletal muscles and may have evolved for fast scanning of the sensory environment.
\end{abstract}

Key words: whisker; vibrissas; whisking; muscle fiber; barrel cortex; myosin heavy chain

\section{Introduction}

In rodents, the facial vibrissas function as important tactile sensors (Vincent, 1912; Gustafson and Felbain-Keramidas, 1977; Brecht et al., 1997). As in other sensory systems, active positioning of sensors plays an important role in vibrissal function, and in most rodents, facial whiskers can be moved. However, the degree to which whiskers are mobile differs among rodents. Some species like rats, hamsters, and mice display a highly specialized pattern of whisker movements referred to as whisking (Welker, 1964; Lee and Woolsey, 1975; Wineski, 1985; Carvell and Simons, 1990). Whisking behavior is strictly rhythmic and occurs at high repetition rates up to $25 \mathrm{~Hz}$. It can involve large amplitude whisker movements $\left(>100^{\circ}\right)$ and occurs mainly in the plane of the whisker row. Thus, whisking is a high-speed behavior with repetition rates that exceed those of most other behaviors displayed by mammals.

Movements of whiskers are generated by two classes of muscles. One class, the intrinsic whisker muscles (also referred to as vibrissal capsular muscle), have their points of attachment completely within the mystacial pad and form a sling around each follicle (Dörfl, 1982). Intrinsic whisker muscles constitute the major share of the whisker pad musculature, and their contrac-

Received Nov. 21, 2003; revised Feb. 25, 2004; accepted Feb. 25, 2004.

This work was supported by the Max-Planck-Society. We thank Randy Bruno and Jack Waters for providing comments on this manuscript.

Correspondence should be addressed to Dr. Michael Brecht, Department of Cell Physiology, Max-Planck-Institute for Medical Research, Jahnstrasse 29, D-69120 Heidelberg, Germany. E-mail: brecht@mpimf-heidelberg.mpg.de. D01:10.1523/JNEUROSCI.5151-03.2004

Copyright $\odot 2004$ Society for Neuroscience $\quad$ 0270-6474/04/243386-08\$15.00/0 tion causes protraction (forward movement) of the vibrissas (Carvell et al., 1991; Berg and Kleinfeld, 2003). A second class of muscles, the extrinsic muscles, anchors external to the mystacial pad, and their contraction results in retraction (backward movement of the vibrissas) (Wineski, 1985; Berg and Kleinfeld, 2003).

A variety of muscle fiber types can be distinguished in skeletal muscle, and the properties of different muscle fiber types are correlated to the cellular (ultrastructure, mitochondria, etc.) and molecular (myosins, metabolic enzymes, etc.) makeup of the respective fibers. The heavy chain portion of the myosin molecule that determines the major functional characteristic of myosin isoforms provides a particularly useful molecular marker for muscle fiber type (Kelly and Rubinstein, 1994; Weiss et al., 1999). The ATPase activity of various myosin heavy chain (MyHC) isoforms can be differentiated and visualized by histochemical staining procedures (Brooke and Kaiser, 1970) or antibody labeling (Hughes et al., 1993). The presence of different MyHC isoforms correlates well with the functional characteristics of the respective fiber type (Pette and Staron, 1990; Staron, 1997). Thus, fiber types are classified according to the MyHC: type 1 with $\mathrm{MyHC1}$, type $2 \mathrm{~A}$ with $\mathrm{MyHC} 2 \mathrm{~A}$, type $2 \mathrm{D}$ with $\mathrm{MyHC} 2 \mathrm{D}$, and type $2 \mathrm{~B}$ with MyHC2B.

Muscle fibers differ in the stability and fatigue resistance of their contractions as well as in the maximum velocity of contraction. Type 1 fibers, so-called slow fibers, generally have high levels of aerobic oxidative enzymes. Type 1 fibers, therefore, show stability and fatigue resistance from a long-lasting supply of ATP derived from oxidation of nutrients provided by the blood. Type 
2 fibers, so-called fast fibers, can be subdivided into three types. Type 2A fibers have oxidative enzymes and are thus fatigue resistant. Type $2 \mathrm{~B}$ and 2D fibers have high levels of anaerobic glycolytic enzymes providing a rapid oxygen-independent source of ATP, but this pathway rapidly depletes glycogen stores, and fatigue develops after brief usage (Hughes et al., 1999). The maximum velocity of contraction $\left(V_{\max }\right)$ for fibers composed of a single MyHC increases in the order $1<2 \mathrm{~A}<2 \mathrm{D}<2 \mathrm{~B}$ (Bottinelli, 1991).

Here, we try to identify structural specializations of whisker musculature that are associated with high-speed whisking behavior. Specifically, we asked the following questions: (1) How do vibrissa movements of whisking (mouse, rat) and non-whisking (guinea pig) species compare? (2) What is the fiber composition of intrinsic whisker musculature? (3) How does the fiber composition of intrinsic whisker musculature differ between whisking and non-whisking rodent species? (4) How does the fiber composition of intrinsic whisker musculature compare with the muscle fiber composition of skeletal muscles?

We found that whisker movements are mediated by a specialized musculature that is distinguished from skeletal muscles by a predominance of fast contracting, fast-fatigable type $2 \mathrm{~B}$ muscle fibers.

\section{Materials and Methods}

Animals. The histology of whisker muscles was based on C57/BL6 mice (11-12 weeks old; $n=10)$, wistar rats $(4-5$ weeks old; $n=6)$, and guinea pigs ( $10-12$ weeks old; $n=2)$ killed by $\mathrm{CO}_{2}$ inhalation. The soleus and the extensor digitorum longus (EDL) muscles were carefully separated from the surrounding tissue, whereas intrinsic whisker muscles of mystacial vibrissas were dissected out together with the complete whisker pad. The soleus muscle is a hind limb muscle that extends the tarsus; it is a muscle known to be involved in the generation of mainly slow movements. The EDL muscle is a hind limb muscle that extends the second, third, fourth, and fifth digit; it is a muscle known to be involved in the generation of mainly fast movements. The intrinsic whisker muscles are involved in vibrissa protraction as explained in detail below.

Videography of whisking motion based on reflex foil labels. Whisker movements were recorded in freely moving animals $(n=10$ mice, $n=6$ rats, $n=2$ guinea pigs). Whisker movements were documented by a videography technique that allowed sampling at a rate of $150 \mathrm{~Hz}$ based on an infrared stroboscope, coupled with an infrared-sensitive video camera. Individual whiskers were labeled with reflex foil to improve contrast. This videography technique was developed to record the movements of single whiskers. Single whisker movement tracking poses three problems: (1) the whiskers move at high velocities requiring short exposure times and a fast recording technique; (2) the whiskers are very thin and offer little optical contrast; and (3) within the 30 whiskers of the array, it is difficult to identify and follow the movements of single whiskers. Very fast recordings with high light gain can be achieved with reflex foil (Junger and Varju, 1990). The reflex foil (7610 High Gain; 3M, Neuss, Germany) is made up of a reflecting sheet of metal loaded with miniature glass balls. The glass balls act as lenses; the net effect of the foil is to reflect light back to its source. Thus, an infrared light-emitting diode (LED) was placed laterally as a light source, and its light was reflected onto the scene by a $45^{\circ}$ inclined half-silvered mirror. The video camera was placed above, videotaping through the mirror. The video camera had a frame rate of $50 \mathrm{~Hz}$ (i.e., a $20 \mathrm{msec}$ exposure time for each frame). The frame onsets were extracted from the video signal, and for each frame three 1 msec flashes of the LED were triggered at $6.67 \mathrm{msec}$ intervals. This led to a stroboscopic image of whisker movements with three whisker positions in each frame, leading to an effective sampling rate of $150 \mathrm{~Hz}$. With adjustment of the focal length of the camera to match the virtual position of the light source in the mirror, the light gain can be maximized. Individual whiskers were marked with a small patch of reflex foil $(0.3 \times 1.5$ $\mathrm{mm}$ ). Adhesive-backed reflex foil patches could be mounted easily on vibrissal shafts for 2- to 10-min-long periods. Even very small patches of reflex foil provided good reflections. This permitted the videotaping of movements of single vibrissas in light or in total darkness purely under infrared illumination.

To determine whether the foil label affected the movements of the labeled whisker, we performed multi-whisker-labeling experiments, in which we labeled two whiskers at different distances from the whisker origin and with different sized foil patches. It has been established that during whisking in air all whiskers engage in very similar movements (Welker, 1964; Carvell and Simons, 1990; but see also Sachdev et al., 2002). When foil patches alter whisker movements, this should result in a deviation of the whisker with the larger and more distant foil patch from the movements of the whisker with the smaller, less distant label. However, such effects were not observed. Whiskers with larger, and more excentric labels moved in perfect coordination with whiskers with small (routinely used) labels or with unlabeled whiskers. Such observations were made both in mice ( $n=10$ double-labeling experiments) and rats ( $n=10$ double-labeling experiments). We noted no systematic difference in whisker movements as a function of foil patch size from one recording session to the next. These results do not rule out the possibility that foil labels affect whisker movement. If so, however, the animals compensate these effects such that no systematic deviation is apparent.

Whisker movements were videotaped in a small cardboard box, with which the animals had never been in contact before the recording session. Mice and rats spontaneously initiated whisking under such conditions. In guinea pigs, however, it was very difficult to evoke intense whisker movements, and these animals had to be continuously presented with a large number of novel objects in the recording box. We labeled exclusively the laterally oriented C- and D-row whiskers. Only those whisking episodes were analyzed in which the animals kept their head upright above the ground performing no or only small translatory movements. Under these conditions, the foil-labeled whiskers moved in the plane of the video camera, and a small tilt $\left(10^{\circ}\right)$ of the whisker against the lateral plane induced only small errors $(\ll 5 \%)$ in angular position estimates.

Whisker movements were analyzed offline. Movies were digitized using a framegrabber card and the Image program (Scion, Frederick, MD). Digitized movies were analyzed frame by frame by manually placing cursors on the position of the foil label and the whisker origin. Similarly, we determined the orientation of the animal's head by placing cursors on two landmarks on the animal's head. Both the head orientation values (which usually changed on a much slower time scale than whisker position values) and angular whisker position values were read out from the Scion program into a table/text file. In a second analysis step, these values were imported into a spread sheet program (Excel) and then used to compute for each foil patch position the angular whisker position relative to the rostrocaudal axis of the animal's head. Translatory movements were recognized by tracking landmarks (like the eye) on the animal's head and were corrected for by adjusting the position of the whisker origin. To determine the frequency content of movements, we generated power spectra by computing Fourier transforms of movement traces.

Reverse transcription-PCR. RNA was isolated from mystacial vibrissa of animals as described by Chomczynski and Sacchi (1987). First-strand cDNA was synthesized from $5 \mu \mathrm{g}$ of total RNA using reverse transcriptase (Invitrogen, Karlsruhe, Germany) and $1 \mu \mathrm{l}$ of $\mathrm{pd}(\mathrm{N})_{6}$ random hexamer (Amersham Pharmacia, Freiburg, Germany). Oligonucleotides were synthesized in the $3^{\prime}$ untranslated regions of four MyHC genes, as described by Sartorius et al. (1998): MyHC1 (sense, 5'-CCAAGGGCCTGAATGAGGAG-3'; antisense, 5' -GCAAAGGCTCCAGGTCTGAG-3'), MYHC2A (sense, 5' -AAGCGAAGAGTAAGGCTGTC-3' ${ }^{\prime}$; antisense, 5' GTGATTGCTTGCAAAGGAA C-3'), MyHC2B (sense, 5' -ACAAGCTGCGGGTGAAGAGC-3'; antisense, 5'-CAGGA CAGTGACAAAGAACG-3'), MyHC2D (sense, 5' -CCAAGTGCAGGAAAGTGACC-3'; antisense, 5'-AGGAAGAGACTGACGAGCTC-3'). The primers were identical for mouse and rat. For guinea pig, only the MyHC2B primers were available for transcript analysis.

PCR was done with Hotstar Taq polymerase (Qiagen, Hilden, Germany) as: denaturation at $94^{\circ} \mathrm{C}$ for $30 \mathrm{sec}$, annealing at $58^{\circ} \mathrm{C}$ for $30 \mathrm{sec}$, primer extension at $72^{\circ} \mathrm{C}$ for $30 \mathrm{sec}$ for a total of $30 \mathrm{cycles}$, followed by 1 cycle of primer extension at $72^{\circ} \mathrm{C}$ for $10 \mathrm{~min}$. Cycle numbers of PCR were 
optimized to yield a linear increase in reaction product. PCR products were visualized directly in ethidium bromide-stained agarose gels. Fluorescence intensities were quantified using IPlab Gel program (Scanlysics, Fairfax, VA).

Myofibrillar ATPase staining. Soleus muscles, EDL muscles, and whole mystacial pads were dissected from animals and embedded in an embedding medium (Sakura, AT Zoeterwoude, The Netherlands). Embedded muscles were frozen rapidly in liquid nitrogen-cooled isopentane and placed on a cryostat at $-20^{\circ} \mathrm{C}$. Thereafter, $10 \mu \mathrm{m}$ longitudinal sections in the mid-portion of the muscles were cut and mounted on polylysinecoated glass slides.

Myofibrillar ATPase staining was performed as described by Brooke and Kaiser (1970). In brief, sections were incubated in acidic buffer (3.5 mm barbital and $3.5 \mathrm{~mm}$ sodium acetate, $\mathrm{pH} 4.6$ ) for $15 \mathrm{~min}$ and then in ATP staining buffer (3.6 mм ATP, $20 \mathrm{~mm}$ barbital, and $18 \mathrm{~mm} \mathrm{CaCl}_{2}, \mathrm{pH}$ 9.4) for $2 \mathrm{hr}$. Incubation in $1 \% \mathrm{CaCl}_{2}$ for $10 \mathrm{~min}$ was followed by incubation in $2 \% \mathrm{CoCl}_{2}$ for $10 \mathrm{~min}$ and in $2 \%\left(\mathrm{NH}_{4}\right)_{2} \mathrm{~S}$ for $1 \mathrm{~min}$. Then sections were dehydrated in 50,70, 80, 95, and $100 \%$ ethanol and mounted on Eukitt (O. Kindler, Freiburg, Germany). Dark-stained fibers (slow fibers) indicate the presence of $\mathrm{MyHC1}$. Fast fibers are recognized as light, unstained fibers containing MyHC2A or intermediate-staining fibers containing $\mathrm{MyHC} 2 \mathrm{~B}$ or $\mathrm{MyHC2D}$ (which represent the fastest fibers). Because the absolute gray values of ATPase stains may vary from trial to trial, we always stained muscles (EDL or soleus) with a roughly known fiber composition together with whisker muscles for internal reference.

Immunochemistry. Cross-sections $(10 \mu \mathrm{m})$ were stained with hematoxylin/eosin to visualize and count muscle fibers. Adjacent sections were used to identify different MyHC forms by isoform-specific antibodies. The sections on glass slides were marked with a PAP pen (G. Kisker, Steinfurt, Germany) and washed briefly in $1 \times$ PBS for $5 \mathrm{~min}$. After incubation in blocking solution (BS; 0.5\% BSA, 2.5\% horse serum, and $0.01 \%$ Triton X-100 in PBS) for $30 \mathrm{~min}$, sections were incubated for $2 \mathrm{hr}$ with primary antibody in BS. Sections were then washed three times for 2 min each in PBS and for 10 min in BS. The secondary antibody in BS was applied for $1 \mathrm{hr}$, and sections were washed four times for $3 \mathrm{~min}$ in PBS. Stained sections were visualized under an Axioplan2 fluorescence microscope (Zeiss, Göttingen, Germany) and imaged using a CCD camera (Intas, Göttingen, Germany).

Primary antibody MY-32 (Sigma, Deisenhofen, Germany) was used to detect MyHC1, NOQ7.5.4.D (Sigma) was used to detect all MyHC2 fibers, and A4.74 (Alexis, Grünberg, Germany) was used to detect MyHC2A (Hughes et al., 1993). Anti-MyHC1, MyHC2, and MyHC2A were used at dilution of 1:1000, 1:200, and 1:10, respectively.

Secondary antibody Alexa 488-labeled goat anti-mouse (Molecular Probes, Leiden, The Netherlands) was used at a dilution of 1:500.

Fiber counts of hematoxylin/eosin, ATPase, and immunochemically stained serial sections. Alternating serial sections were stained with hematoxylin/eosin, ATPase staining (as described above), and anti-MyHC antibodies as described above. Images of stained cross-sections were captured with a CCD camera. In soleus ( $n=36$ muscles in mice, $n=10$ muscles in rats, $n=4$ muscles in guinea pigs) and EDL ( $n=14$ muscles in mice, $n=10$ muscles in rats, $n=4$ muscles in guinea pigs) muscles, the relative number of fiber types could easily be scored based on ATPasestained sections, by judging the relative intensity of the precipitate stain. Intrinsic whisker muscles (from $n=8$ whisker pads in mice, from $n=6$ whisker pads in rats, from $n=4$ whisker pads in guinea pigs) were considerably more difficult to score because of their homogeneous appearance in the ATPase stain and the difficulty in delineating the outlines of these very small muscle fibers. Thus, intrinsic whisker muscles were scored based on multiple stains using the hematoxylin/eosin stain for delineating individual fibers and relying on both the ATPase staining and the immunochemical staining for determining the fiber type.

\section{Results}

Whisker movements in mice, rats and guinea pigs: qualitative and quantitative comparisons of movements

In all three species, whisker movements were observed. Novel environments and interactions with novel objects triggered the most intense movements, suggesting a function of whisker movements in exploratory behavior in all three species. Large whisker movements $\left(>40^{\circ}\right)$ were common in mice and rats, whereas they were rare but not absent in guinea pigs. In mice and rats, large whisker movements often occurred in bouts of movements (whisking), whereas in guinea pigs large whisker movements often occurred in isolation. Bouts of movements in mice and rats consisted of a rhythmic series of several protractions and retractions. Within a bout of movements, protraction/retraction amplitudes rose and fell continuously. The length of such a whisking bout varied considerably, and a single bout consisted of 4 to $>20$ protractions and retractions. Under our experimental conditions, most whisking bouts were brief (5-10 protractions and retractions) and were shorter than $1 \mathrm{sec}$ in mice and shorter than $2 \mathrm{sec}$ in rats. Thus, in our behavioral settings, whisking both in rats and in mice was restricted to brief episodes. However, when rats approach or search for their home cage, whisking can occur for extended periods of tens of seconds (K. Ganguly and D. Kleinfeld, personal communication).

All three species kept their whiskers either in a backward, nonerected resting position or the whiskers were moving. Whereas animals can keep the whiskers protracted (for example, when they cross gaps), they always do so only for brief periods. In this respect, whisker movements differ from limb movements in which one observes that a variety of postures can be assumed for prolonged periods.

To provide a better impression of the quantitative differences in whisker movements, we show episodes of particularly intense (i.e., sustained high amplitude) whisker movements for each species in Figure 1. Such episodes were common and relatively stereotyped in mice (Fig. $1 A$ ) and rats (Fig. $1 B$ ). However, intense whisker movements were rare in guinea pigs. The trace displayed in Figure $1 C$ shows the most intense bout of movements observed ( $3 \mathrm{hr}$; two animals). Although whisking frequency was relatively stable, angular amplitudes and velocities of whisking varied widely with the behavioral setting but were generally largest in mice (Fig. 1A, middle) and smallest in guinea pigs (Fig. $1 C$, middle).

Table 1 gives quantitative values of movement parameters as they were observed for intense whisker movements in mice, rats, and guinea pigs. Whisking in mice occurred with frequencies between 14 and $24 \mathrm{~Hz}$ in mice (Table 1; Fig. 1A, right) and between 5 and $12 \mathrm{~Hz}$ in rats (Table 1 ; Fig. $1 \mathrm{~B}$, right). In guinea pigs, large whisker movements often occurred in isolation. Bouts of movements were less rhythmic than in rats or mice, and whisking frequencies were $\leq 5 \mathrm{~Hz}$ (Table 1; Fig. $1 C$, right). The rhythmicity of mouse and rat whisker movements led to sharp peaks in the power spectra of the movement recordings (Fig. 1, right). Peaks were even sharper when the analysis was restricted to a single bout of movements (Berg and Kleinfeld, 2003) instead of analyzing of an episode, which contained several whisking bouts and in which movement amplitudes increased and decreased multiple times. Angular movement amplitudes were comparable in mice and rats but were smaller in guinea pigs. Velocities of protraction and retraction were highest in mice, smaller in rats, and smallest in guinea pigs (Table 1), whereby the species differences were more pronounced for average angular velocities than for peak velocities.

\section{Anatomy of the mystacial pads and identification of intrinsic whisker muscles}

Figure $2 A$ represents a schematic view of the mouse mystacial pad. Intrinsic whisker muscles form slings surrounding whisker 

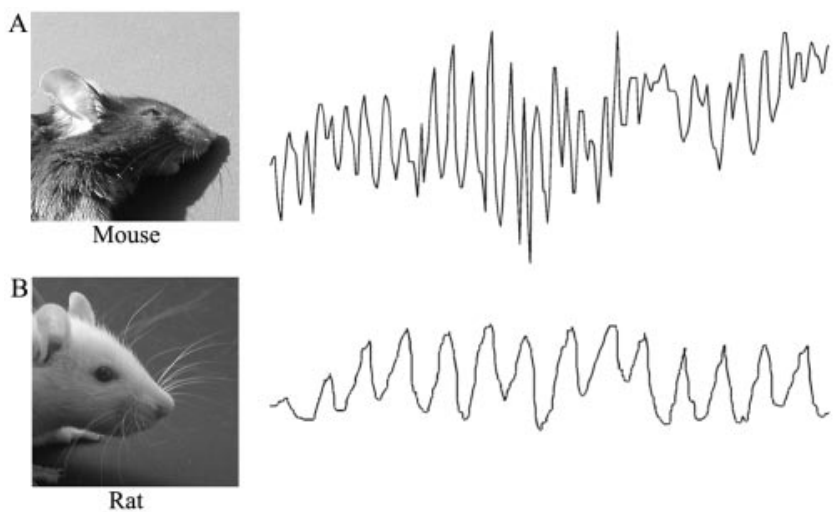

Rat
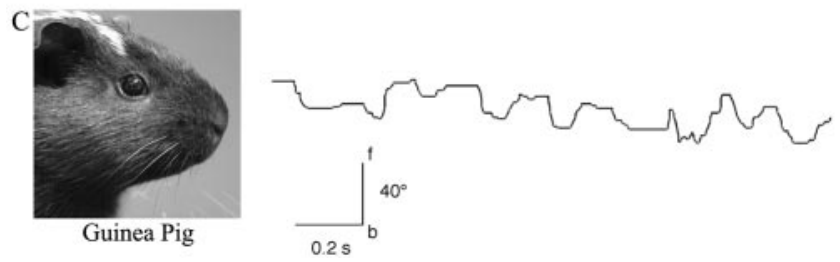

Figure 1. Whisker movements in mouse, rat, and guinea pig. A, Left, Side view of a mouse head and whiskers. Middle, Back (b) and forth ( $\mathrm{f}$ ) movements (angular positions) of whisker $\mathrm{C} 2$ of a mouse during a whisking episode. Right, Power spectrum of the movement trace. $B$, Left, Rat head. Middle, Rat whisker movements of whisker C2 during a whisking episode. Right, Power spectrum. Conventions are as in A. C, Left, Guinea pig head. Middle, Guinea pig whisker movements of whisker D2 during an episode of intense whisker movements. Right, Power spectrum. Conventions are as in $A$. All power spectra have been normalized to the same maximum peak height.

Table 1. Movement parameters during episodes of intense whisker movements

\begin{tabular}{|c|c|c|c|}
\hline & Mouse & Rat & Guinea pig \\
\hline Whisking frequency (Hz) & $20.4 \pm 2.8$ & $8.4 \pm 1.5$ & $4.7 \pm 1.1$ \\
\hline \multicolumn{4}{|l|}{ Mean angular amplitude during } \\
\hline whisking $\left({ }^{\circ}\right)$ & $55 \pm 17$ & $56 \pm 14$ & $25 \pm 11$ \\
\hline \multicolumn{4}{|l|}{ Average angular velocity for full } \\
\hline sweeps of protraction ( $\% / \mathrm{sec})$ & $2074 \pm 588$ & $717 \pm 186$ & $332 \pm 76$ \\
\hline \multicolumn{4}{|l|}{ Average angular velocity for full } \\
\hline sweeps of retraction $(\% / \mathrm{sec})$ & $2436 \pm 791$ & $1484 \pm 752$ & $553 \pm 276$ \\
\hline \multicolumn{4}{|l|}{$\begin{array}{l}\text { Maximum angular velocity for } \\
\text { full sweeps of protraction }\end{array}$} \\
\hline$(\% / \mathrm{sec})$ & $3105 \pm 1429$ & $956 \pm 385$ & $447 \pm 202$ \\
\hline \multicolumn{4}{|l|}{$\begin{array}{l}\text { Maximum angular velocity for } \\
\text { full sweeps of retraction }\end{array}$} \\
\hline$(\% / \mathrm{sec})$ & $3700 \pm 2194$ & $2022 \pm 913$ & $803 \pm 187$ \\
\hline $\begin{array}{l}\text { Peak angular velocity measured } \\
\text { during protraction }\left({ }^{\circ} / \mathrm{sec}\right)^{a}\end{array}$ & 5925 & 1950 & 1350 \\
\hline $\begin{array}{l}\text { Peak angular velocity measured } \\
\text { during retraction }\left({ }^{\circ} / \mathrm{sec}\right)^{a}\end{array}$ & 9900 & 3500 & 1800 \\
\hline
\end{tabular}

Values are given as means \pm SD. Data refer to 20 episodes of whisking in mice and rats and 5 episodes of intense whisker movements in guinea pigs.

${ }^{a}$ Values refer to the maximum value measured across the complete observation episode.

follicles (i; Fig. 2A,C), and extrinsic whisker muscles are anchored to the skin (e; Fig. $2 A$.) The attachment of intrinsic and extrinsic muscles to the whisker allows protraction and retraction, respectively (Fig. $2 \mathrm{~A}$ ). We prepared $10 \mu \mathrm{m}$ longitudinal sections of mystacial pads perpendicular to the skin and orthogonal to the orientation of whisker rows, as shown in Figure $2 \mathrm{~A}$. In hematoxylin/eosin-stained sections, muscle fibers can be recognized by a dark red/violet color, and Figure $2 B$ shows three follicles surrounded by a layer of thin intrinsic whisker muscle fibers. Hematoxylin/eosin-stained sections through whole whisker pads indicate that, by far, most of the muscle fibers in the whisker pad belong to the intrinsic whisker muscles. This was true for all three
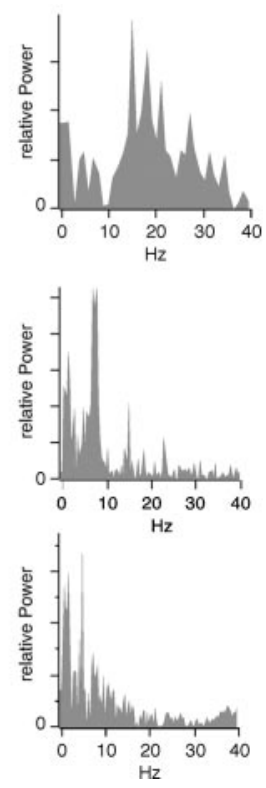

species studied. Figure $2 C$ shows a magnified view of a whisker follicle and the surrounding intrinsic whisker muscle fibers. Figure $2 C$ also demonstrates that intrinsic whisker muscle can be identified easily by its characteristic arrangement around the follicle.

\section{MyHC isoforms mRNA expression in} extracts from whole mystacial pads Extracts of whole mystacial pads were made to determine mRNA expression of $\mathrm{MyHC}$ isoforms in mystacial pads from mouse, rat, and guinea pig by reverse transcription-PCR (RT-PCR). Because these extracts contain intrinsic and extrinsic whisker muscles and possibly small amounts of other muscle tissue, it is not possible to precisely determine the fiber composition of whisker muscles. Nevertheless, gross $\mathrm{MyHC}$ isoform mRNA levels can be determined with molecular resolution that cannot be achieved by ATPase staining or immunochemistry.

Results are summarized in Table 2, revealing in mice predominant expression of MyHC2B mRNA and low levels of MyHC2D mRNA. In rats, we detected only MyHC2B transcripts and none of the other isoform transcripts tested. In guinea pigs, no appropriate primers for $\mathrm{MyHC1}, \mathrm{MyHC2A}$, and MyHC2D mRNAs were available, and we therefore cannot comment on the relative expression of $\mathrm{MyHC}$ isoforms in guinea pigs. However, we detected expression of the MyHC2B mRNA.

\section{Comparison of muscle fiber types in soleus, EDL, and intrinsic whisker muscle}

We performed myofibrillar ATPase staining, as described by Brooke and Kaiser (1970), to determine the fiber types of intrinsic whisker muscle and various skeletal muscles. Figure 3 shows cross-sections of soleus, EDL, and intrinsic whisker muscles of mouse, rat, and guinea pig after ATPase staining at $\mathrm{pH}$ 4.6.

In mice, the intrinsic whisker muscles (Fig. $3 A$ ) were composed of type $2 \mathrm{~B}$ or $2 \mathrm{D}$ only. The soleus muscle (Fig. $3 B$ ) contained mainly type 1 and type $2 \mathrm{~A}$ fibers, with a few type $2 \mathrm{~B}$ or type 2D (intermediate) fibers, whereas the EDL muscle (Fig. $3 \mathrm{C}$ ) was predominantly composed of type $2 \mathrm{~A}$ and $2 \mathrm{~B}$ or $2 \mathrm{D}$ fibers, with only a few type 1 fibers.

In rats, the intrinsic whisker muscles (Fig. 3D) were predominantly composed of type $2 \mathrm{~B}$ or $2 \mathrm{D}$ with a small number of type 1 fibers. The soleus muscle (Fig. 3E) contained mainly type 1 fibers, with a small number of type $2 \mathrm{~A}$ and a few type $2 \mathrm{~B}$ or type $2 \mathrm{D}$ fibers, whereas the EDL muscle (Fig. $3 F$ ) predominantly comprised type $2 \mathrm{~A}$ and type $2 \mathrm{~B}$ or $2 \mathrm{D}$ fibers, with smaller number of type 1 fibers.

In guinea pigs, the intrinsic whisker muscles (Fig. $3 G$ ) contained type $2 \mathrm{~B}$ or type $2 \mathrm{D}$ fibers, with small number of type $2 \mathrm{~A}$ and a few type 1 fibers. The soleus muscle (Fig. $3 H$ ) only contained type 1 fibers, whereas the EDL muscle (Fig. 3I) was predominantly composed of type $2 \mathrm{~A}$ and type $2 \mathrm{~B}$ or $2 \mathrm{D}$ fibers, with a few type 1 fibers.

It should be kept in mind that myofibrillar ATPase staining does not differentiate between MyHC2B- or MyHC2D-containing fibers (both fiber types display intermediate staining). 

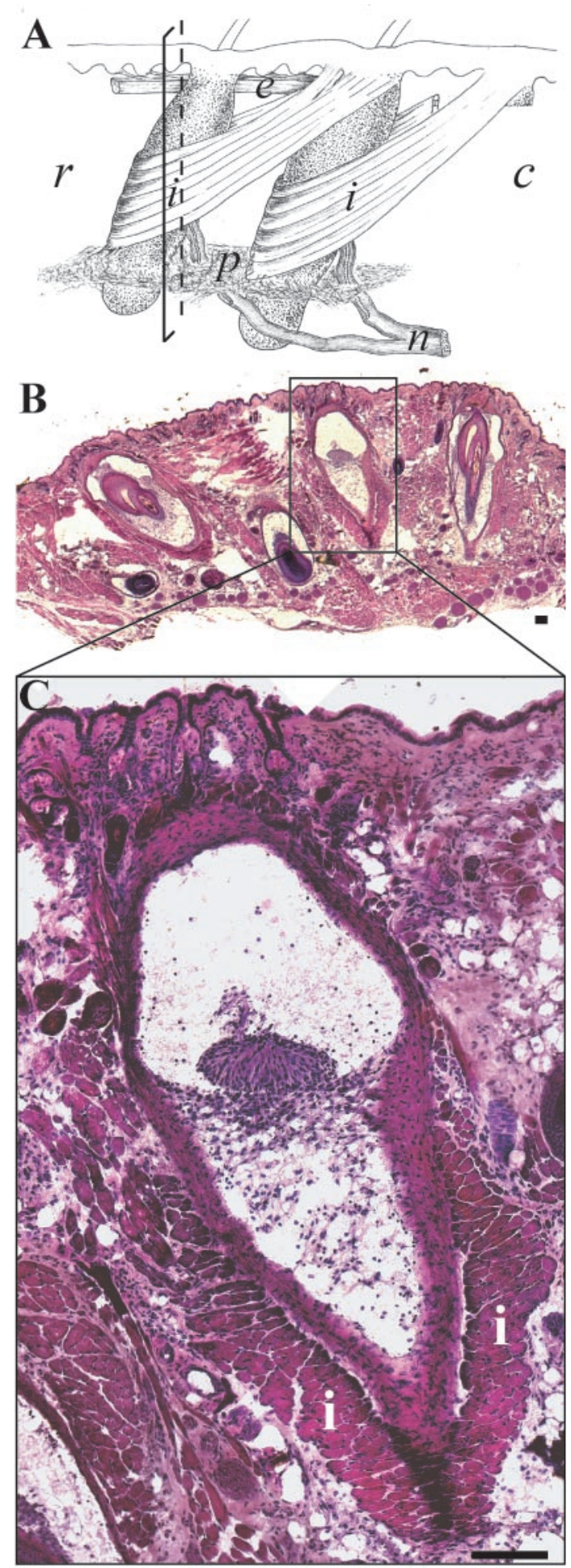

Figure 2. Cross-section of a mouse mystacial pad. A, Schematic overview of vibrissa follicles [after Dörfl (1982)]. r, Rostral; c, caudal; n, motor nerve; p, plate; i, intrinsic whisker muscle; e, extrinsic whisker muscle; rectangle marks longitudinal section across mystacial pad as shown in $B$ and C. B, Mystacial pad stained with hematoxylin/eosin. C, Magnified view from B as outlined by rectangle. i, Intrinsic whisker muscles. Scale bar, $100 \mu \mathrm{m}$.

Also, the intrinsic whisker muscle fibers are smaller than soleus and EDL muscles, and the boundaries and shape of the single fibers were not outlined clearly in each case. Therefore, it is not possible to characterize fiber types of intrinsic whisker muscle as exactly as for soleus or EDL muscle using the myofibrillar ATPase staining.
Table 2. MyHC isoform mRNAs in mystacial pads

\begin{tabular}{lllll}
\hline \multicolumn{5}{l}{ Proportion of } \\
\hline & MyHC & MyHoform mRNAs (\%) & MyHC2B & MyHC2D \\
Mouse & nd & nd & $89.5 \pm 3.54$ & $10.5 \pm 3.54$ \\
Rat & nd & nd & 100 & nd \\
Guinea pig & $?$ & $?$ & + & $?$ \\
\hline
\end{tabular}

Total RNA was extracted from whole mystacial pads of mouse, rat, and guinea pig and analyzed by RT-PCR. The fluorescence intensities of the ethidium bromide-stained PCR products as observed on agarose gel electrophoresis were used to compare the MyHC isoform mRNA levels in different species. nd, Not detected; ?, no appropriate primers for these mRNAs were available.

Immunochemical staining of $\mathrm{MyHC}$ isoforms in the whisker pad and muscle fiber counts

To ascertain the exact distribution of fiber types in the intrinsic whisker muscle of all three species, we used isoform-specific anti$\mathrm{MyHC}$ antibodies. Because it is difficult to exactly delineate the shape of each fiber after immunochemical staining, we prepared serial sections and performed hematoxylin/eosin staining and immunochemical staining in alternating sections.

Figure 4 shows the distribution of fibers in intrinsic whisker muscle as revealed by antibody labeling. The hematoxylin/eosin staining was used to visualize the morphology of intrinsic whisker muscles and to count the total number of fibers per muscle section (Fig. 4A,E,I). The fibers of intrinsic whisker muscles from mouse (Fig. 4C) reacted exclusively with anti-MyHC2 antibodies, and there were no fibers stained by anti-MyHC1 (Fig. $4 B$ ) or anti-MyHC2A (Fig. 4D) antibodies. Intrinsic whisker muscles of the rat (Fig. $4 G$ ) were stained by anti-MyHC2 antibodies and, in a few cases, by anti-MyHC1 antibodies (Fig. $4 F$ ), but there was no labeling by anti-MyHC2A antibodies (Fig. $4 H$ ). Intrinsic whisker muscles of guinea pigs (Fig. $4 \mathrm{~K}$ ) also reacted predominantly with anti-MyHC2. Some fibers were labeled by anti-MyHC2A (Fig. $4 L$ ) and infrequently also by anti-MyHC1 (Fig. 4J) antibodies.

The MyHC-typing of muscle fibers, together with the data from myofibrillar ATPase staining, are shown in Figure 5. As explained in Materials and Methods, MyHC-typing of muscle fibers in soleus and EDL was done by ATPase staining, whereas MyHC-typing of muscle fibers in the intrinsic whisker muscles was based on serial sections stained by hematoxylin/eosin, ATPase staining, and antibodies. Because both myofibrillar ATPase staining and immunochemical staining cannot distinguish MyHC2B- and MyHC2D-containing fibers, we refer to these fibers as MyHC2B/2D fibers here and in Fig. 5.

Intrinsic whisker muscles of mice were composed exclusively of type MyHC2B/2D fibers, and mRNA expression suggests that the predominant fraction of intrinsic whisker muscle fibers was of type $2 \mathrm{~B}(\geq 90 \%)$. Intrinsic whisker muscles of rats were composed of fiber type MyHC1 (10 $\pm 1 \%)$ and MyHC2B/2D (90 \pm $1 \%)$. Because no MyHC2D mRNA was detectable in these muscles, the data suggest that $\sim 90 \%$ of rat intrinsic whisker muscles fibers were of type $2 \mathrm{~B}$. Intrinsic whisker muscles of guinea pigs were composed of fiber type MyHC1 ( $\pm \pm 1 \%$ ), MyHC2A (19 \pm $1 \%)$, and $\mathrm{MyHC} 2 \mathrm{~B} / 2 \mathrm{D}(78 \pm 1 \%)$.

The MyHC-typing of muscle fibers of skeletal muscles led to strikingly different results (Fig. 5). Intrinsic whisker muscles all three species are characterized by their high content of type MyHC2B/2D fibers and differ from skeletal muscles even when comparing them to the EDL, a muscle specialized for fast movements.

\section{Fiber composition of extrinsic whisker muscles}

In our study, we focused on intrinsic whisker muscles because they form the bulk of the whisker musculature and are easily 

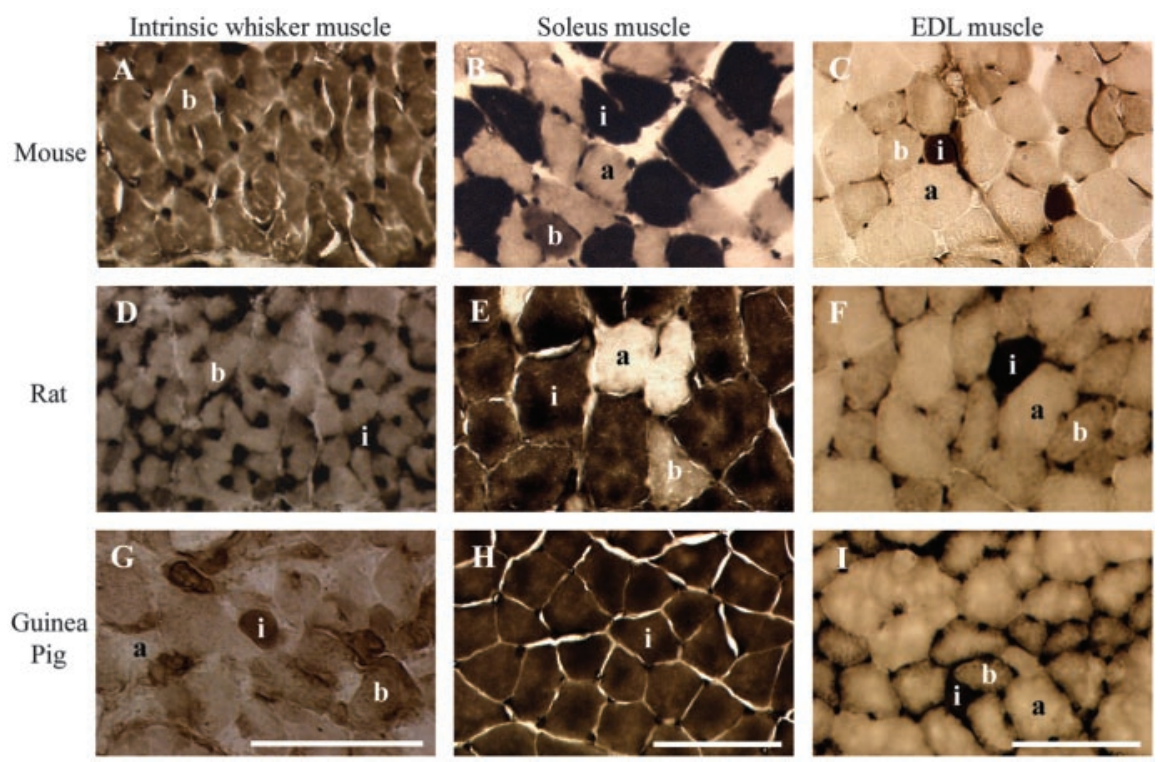

Figure 3. Serial cross-sections of different muscle types from mouse, rat, and guinea pig. Cross-sections of intrinsic whisker, soleus, and EDL muscles were subjected to myofibrillar ATPase staining at pH 4.6: mouse $(A-C)$, rat $(D-F)$, and guinea pig $(G-l)$. Intrinsic whisker muscle of mystacial pads $(A, D, G)$, soleus muscle $(B, E, H)$, and EDL muscle $(C, F, I)$. i, Muscle fiber type $1 ; a$, muscle fiber type $2 A$; $b$, muscle fiber type $2 B$ or $2 D$. Scale bars, $50 \mu \mathrm{m}$; applies to all columns.
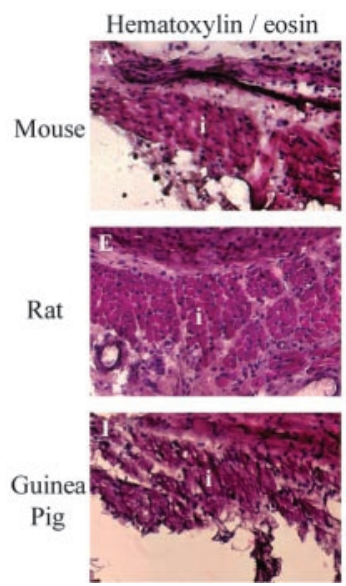
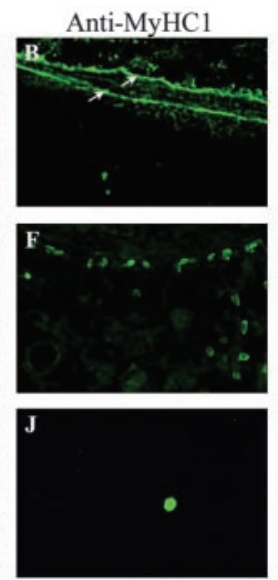

Anti-MyHC2
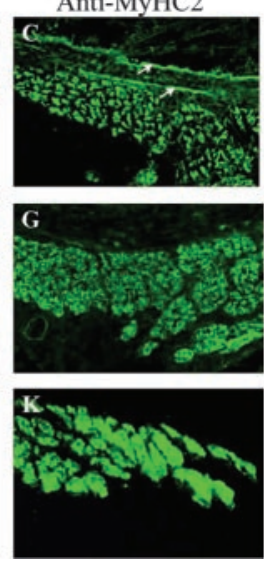

Figure 4. Immunochemical characterization of intrinsic whisker muscles. Serial cross-sections of intrinsic whisker muscles from mouse $(A-D)$, rat $(E-H)$, and guinea pig $(I-L)$ were stained with specific MyHC isoforms. $A, E$, I, Hematoxylin/eosin staining of adjacent sections were done to visualize individual muscle fibers. MY-32 antibodies were used to detect MyHC1-containing fibers $(B, F, J), N 0 Q 7.5 .4$.D antibodies were used to detect $M y H C 2$-containing fibers $(C, G, K)$, and $A 4.74$ antibodies were used to detect MyHC2A-containing fibers $(D, H, L)$. Anti-MyHC1, MyHC2, and MyHC2A were used at a dilution of 1:1000, 1:200, and 1:10, respectively. Arrows indicate the wall of the vibrissal capsule, which in mice shows an unspecific (nonmuscular) antibody signal. i, Intrinsic whisker muscle. Scale bar, $100 \mu \mathrm{m}$.

identified by their characteristic arrangement around the follicle. Extrinsic whisker muscles run as thin bundles below the skin and are less easily identified (Dörfl, 1982; Wineski, 1985). Occasionally, we detected thin round bundles of muscle fibers below the skin that could be followed through multiple sections. Preliminary evidence suggests that, in the species investigated here, these putative extrinsic whisker muscles were also predominantly composed of fast type 2B fibers: (1) such bundles were stained specifically by anti-MyHC2 antibodies (data not shown); (2) ATPase yielded intermediately stained fibers, the staining of which was comparable with the staining of type $2 \mathrm{~B}$ fibers of the intrinsic whisker muscle; and (3) the mRNA expression suggests the predominant expression of $\mathrm{MyHC} 2 \mathrm{~B}$ transcripts. Because of the
Anti-MyHC2A

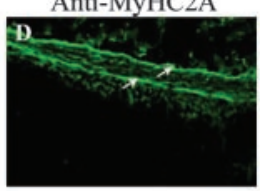

H
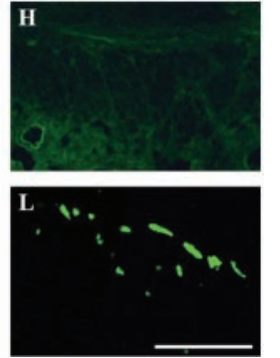

small sample of muscles studied here, we could not determine the exact distribution and $\mathrm{MyHC}$ composition of muscle fibers of extrinsic whisker muscles.

\section{Discussion}

Mice, rats, and guinea pigs can generate fast and large amplitude whisker movements. The main species difference in whisker movements consists of the fact that guinea pigs do not show bouts of fast, strictly rhythmic whisker protractions and retractions (i.e., whisking). The average speed of whisker movements is much lower in guinea pigs than in mice and rats. In all three species, intrinsic whisker muscles are composed predominantly of fast type $2 B / 2 D$ fibers. In mice, type $2 B / 2 D$ fibers seem to constitute the only fiber type, whereas in rats we also observed $\sim 10 \%$ of slow type 1 fibers, and in guinea pigs we observed $\sim 3 \%$ slow type 1 fibers and 20\% of fast type $2 \mathrm{~A}$ fibers. The MyHC transcript analysis suggests that $\geq 90 \%$ of the type $2 B / 2 D$ fibers in rats and mice actually correspond to type $2 \mathrm{~B}$ fibers. The combination of methods used here allowed us to determine the fiber type composition of intrinsic whisker muscle with a high degree of certainty. The MyHC transcript analysis by RT-PCR determines with high specificity the expression levels of individual MyHC mRNAs, whereas ATPase staining of $\mathrm{MyHC}$ isoforms as well as antibody staining extends this analysis on the protein level and allows us to classify muscles according to their content of different $\mathrm{MyHC}$ isoforms. This information will help us to understand how muscle function is regulated.

\section{Type 2B fibers predominate in whisking musculature}

Our results on whisker movements are in agreement with previous studies on the whisking behavior of rats (Welker, 1964; Carvell and Simons, 1990; Harvey et al., 2001; Sachdev et al., 2002; Berg and Kleinfeld, 2003), mice (Lee and Woolsey, 1975), and informal observations on guinea pigs (Woolsey et al., 1975). Our observations on the anatomy of the whisker pad are consistent with the findings from mice (Dörfl, 1982) and hamsters (Wineski, 1985).

Very little work has been done on the muscle fiber composition of the whisker muscles. Wineski (1985), after pioneering work on the classification of whisker muscles, published a number of preliminary results on fiber types of whisker muscles. These studies on hamsters, rats, and guinea pigs (Wineski et al., 1992; Wineski and Pitts, 1994) were based on ATPase stains and also described a majority of fast type 2 fibers in the whisker pad. In contrast with our results, these studies reported a predominance of type 2A fibers in the whisker pad (Wineski et al., 1992; 
Wineski and Pitts, 1994). However, it must be emphasized that type $2 \mathrm{~A}$ and $2 \mathrm{~B}$ fibers can be difficult to distinguish in ATPase staining. Our additional analyses based on mRNA levels and antibody labeling suggests that, in fact, $2 \mathrm{~B}$ and not $2 \mathrm{~A}$ fibers are the dominant fiber type of the whisker musculature.

In most respects, our findings on the fiber composition of soleus and EDL muscles confirm previous findings (Hughes et al., 1999; Totsuka et al., 2003). However, in our study we observed a lower fraction of $2 \mathrm{~B}$ fibers in the EDL than previously reported (Hughes et al., 1999); most likely, this difference results from the fact that our sample of fibers of the EDL muscle came from more axial parts of the EDL, which are known to consist of a lower percentage of 2B fibers (Lyons et al., 1983; Narusawa et al., 1987).

\section{Evolutionary aspects}

The fiber composition of a muscle reflects the characteristics of the movements the muscle is involved in. The soleus muscle, a muscle mainly generating slow movements, contains predominantly type 1 and type 2A fibers, with small proportions of type 2B fibers, whereas the EDL muscle, a fast muscle, predominantly contains type $2 \mathrm{~B}$ fibers, with a smaller portion of type $2 \mathrm{~A}$ fibers (Schmalbruch, 1985).

Comparison of the fiber composition of these muscles with intrinsic whisker muscle shows that whisker movements are generated by a musculature that is unique in its large fraction of type $2 \mathrm{~B}$ fibers. Type $2 \mathrm{~B}$ fibers provide the highest twitch velocity (Bottinelli, 1991; Schiaffino and Reggiani, 1996). High contraction speed does not come for free, however, and is associated with high rates of ATPase activity (Barany, 1967). Thus, our observations suggest that the need for high contraction speed may have been a driving force in the evolution of whisker muscles. This idea is also consistent with the fact that mice, which perform the fastest whisker movements of the three species studied, have exclusively type $2 \mathrm{~B}$ fibers and that rats, which perform faster whisker movements than guinea pigs, have a higher percentage of type $2 \mathrm{~B}$ fibers than guinea pigs.

Another feature that distinguishes type 2B fibers from other muscle fibers is their high susceptibility to fatigue. The fact that under most conditions both rats and mice whisk only for brief periods and that the whiskers rarely assume a constant protracted position might be related to this lack of fatigue resistance. However, under certain conditions at least, rats seem to be able to whisk for extended periods (Ganguly and Kleinfeld, personal communication), making this idea less compelling; it would be worth investigating whether animals meet their metabolic limits after such extended episodes of whisking. For skeletal muscles involved in the locomotion of predators, it has been observed that sedentary predators like cats and lions that engage in sprints have a large fraction of type 2B fibers (Armstrong et al., 1977). In contrast, the more continuously active dogs lack type $2 \mathrm{~B}$ fibers (Armstrong et al., 1982; Snow et al., 1982). In analogy, one might argue that whisking occurs in a more "sprint-like" than continuous manner, although it is not strictly limited to very brief episodes. Finally, it has been suggested that type $2 \mathrm{~B}$ fibers might be advantageous because of their low-energy demands during periods of inactivity (Burke, 1994), but proof for this idea is pending.
It seems to be the rule rather than the exception that muscles involved in generating movements of sensory organs are specialized for high-speed contractions. Thus, it was shown that in extraocular muscles of the eye (Wieczorek et al., 1985; Sartore et al., 1987 ) and in the tensor tympani muscle of the ear (Mascarello et al., 1982) specialized unconventional myosin isoforms are expressed that are thought to mediate very fast contractions.

We conclude that the high-speed movements of whiskers are mediated by a specialized musculature predominated by fast contracting type $2 \mathrm{~B}$ fibers, and we argue that such a high-speed motor apparatus may have evolved for fast scanning of the sensory environment.

\section{References}

Armstrong RB, Marum P, Saubert 4th CW, Seeherman HJ, Taylor CR (1977) Muscle fiber activity as a function of speed and gait. J Appl Physiol 43:672-677.

Armstrong RB, Saubert 4th CW, Seeherman HJ, Taylor CR (1982) Distribution of fiber types in locomotory muscles of dogs. Am J Anat 163:87-98.

Barany M (1967) ATPase activity of myosin correlated with speed of muscle shortening. J Gen Physiol [Suppl] 50:197-218.

Berg RW, Kleinfeld D (2003) Rhythmic whisking by rat: retraction as well as protraction of the vibrissae is under active muscular control. J Neurophysiol 89:104-117.

Bottinelli R, Schiaffino S, Reggiani C (1991) Force-velocity relationship and myosin heavy chain isoform compositions of skinned fibers from rat skeletal muscle. J Physiol (Lond) 437:655-672.

Brecht M, Preilowski B, Merzenich MM (1997) Functional architecture of the mystacial vibrissae. Behav Brain Res 84:81-97.

Brooke MH, Kaiser KK (1970) Three "myosin ATPase" systems: the nature of their $\mathrm{pH}$ lability and sulfhydryl dependence. J Histochem Cytochem 18:670-672.

Burke RE (1994) Physiology of motor units. In: Myology, Ed 2 (Engel AG, Franzini-Armstrong C, eds), pp 464-483. New York: McGraw-Hill.

Carvell GE, Simons DJ (1990) Biometric analyses of vibrissal tactile discrimination in the rat. J Neurosci 10:2638-2648.

Carvell GE, Simons DJ, Lichtenstein SH, Bryant P (1991) Electromyographic activity of mystacial pad musculature during whisking behavior in the rat. Somat Motor Res 8:159-164.

Chomczynski P, Sacchi N (1987) Single-step method of RNA isolation by acid guanidinium thiocyanate-phenol-chloroform extraction. Anal Biochem 162:156-169.

Dörfl J (1982) The musculature of the mystacial vibrissae of the white mouse. J Anat 135:147-154.

Gustafson JW, Felbain-Keramidas SL (1977) Behavioral and neural approaches to the function of the mystacial vibrissae. Psychol Bull 84:477-488. 
Harvey MA, Sachdev RN, Zeigler HP (2001) Cortical barrel field ablation and unconditioned whisking kinematics. Somat Motor Res 18:223-227.

Hughes SM, Chi M, Karsch-Mizrachi I, Travis M, Silberstein L, Leinwand LA, Blau HM (1993) Three slow myosin heavy chains sequentially expressed in developing mammalian skeletal muscle. Dev Biol 158:183-199.

Hughes SM, Chi MM, Lowry OH, Gundersen K (1999) Myogenin induces a shift of enzyme activity from glycolytic to oxidative metabolism in muscles of transgenic mice. J Cell Biol 145:633-642.

Junger W, Varju D (1990) Drift compensation and its sensory basis in waterstriders (Gerris paludum F.). J Comp Physiol [A] 167:441-446.

Kelly AM, Rubinstein NA (1994) The diversity of muscle fiber types and its origin during development. In: Myology, Ed 2 (Engel AG, FranziniArmstrong C, eds), pp 119-133. New York: McGraw-Hill.

Lee KJ, Woolsey TA (1975) A proportional relationship between peripheral innervation density and cortical neuron number in the somatosensory system of the mouse. Brain Res 99:349-353.

Lyons GE, Haselgrove J, Kelly AM, Rubinstein NA (1983) Myosin transitions in developing fast and slow muscles of the rat hindlimb. Differentiation 25:168-175.

Mascarello F, Carpene E, Veggetti A, Rowlerson A, Jenny E (1982) The tensor tympani muscle of cat and dog contains IIM and slow-tonic fibres: an unusual combination of fibre types. J Muscle Res Cell Motil 3:363-374.

Narusawa M, Fitzsimons RB, Izumo S, Nadal-Ginard B, Rubinstein NA, Kelly AM (1987) Slow myosin in developing rat skeletal muscle. J Cell Biol 104:447-459.

Pette D, Staron RS (1990) Cellular and molecular diversities of mammalian skeletal muscle fibers. Rev Physiol Biochem Pharmacol 116:1-76.

Sachdev RN, Sato T, Ebner FF (2002) Divergent movement of adjacent whiskers. J Neurophysiol 87:1440-1448.

Sartore S, Mascarello F, Rowlerson A, Gorza L, Ausoni S, Vianello M, Schiaffino S (1987) Fibre types in extraocular muscles: a new myosin isoform in the fast fibres. J Muscle Res Cell Motil 8:161-172.

Sartorius CA, Lu BD, Acakpo-Satchivi L, Jacobsen RP, Byrnes WC, Leinwand
LA (1998) Myosin heavy chains IIa and IId are functionally distinct in the mouse. J Cell Biol 141:943-953.

Schiaffino S, Reggiani C (1996) Molecular diversity of myofibrillar proteins: gene regulation and functional significance. Physiol Rev 76:371-423.

Schmalbruch H (1985) Skeletal muscle. Berlin: Springer.

Snow DH, Billeter R, Mascarello F, Carpene E, Rowlerson A, Jenny E (1982) No classical type IIB fibres in dog skeletal muscle. Histochemistry 75:53-65.

Staron RS (1997) Human skeletal muscle fiber types: delineation, development, and distribution. Can J Appl Physiol 22:307-327.

Totsuka Y, Nagao Y, Horii T, Yonekawa H, Imai H, Hatta H, Izaike Y, Tokunaga T, Atomi Y (2003) Physical performance and soleus muscle fiber composition in wild-derived and laboratory inbred mouse strains. J Appl Physiol 95:720-727.

Vincent SB (1912) The function of vibrissae in the behavior of the white rat. Behav Monographs 1:7-81.

Weiss A, Schiaffino S, Leinwand LA (1999) Comparative sequence analysis of the complete human sarcomeric myosin heavy chain family: implications for functional diversity. J Mol Biol 290:61-75.

Welker WI (1964) Analysis of sniffing of the albino rat. Behaviour 22:223-244.

Wieczorek DF, Periasamy M, Butler-Browne GS, Whalen RG, Nadal-Ginard B (1985) Co-expression of multiple myosin heavy chain genes, in addition to a tissue-specific one, in extraocular musculature. J Cell Biol 101:618-629.

Wineski LE (1985) Facial morphology and vibrissal movement in the golden hamster. J Morphol 183:199-217.

Wineski LE, Pitts SA (1994) Facial muscle fiber types and exploratory behavior in rodents. Abstracts Fourth International Congress of Vertebrate Morphology. J Morphol 220:411.

Wineski LE, Pitts SA, Weeks OI (1992) Fiber type diversity in the facial muscles of rodents. Soc Neurosci Abstr 18:1558.

Woolsey TA, Welker C, Schwartz RH (1975) Comparative anatomical studies of the SmL face cortex with special reference to the occurrence of "barrels" in layer IV. J Comp Neurol 164:79-94. 